\title{
ANÁLISE NUTRICIONAL DA FRUTA-DE-LOBO (Solanum lycocarpum St. Hil.) DURANTE O AMADURECIMENTO
}

\author{
ENIO NAZARÉ DE OLIVEIRA JUNIOR ${ }^{1}$ \\ CUSTÓDIO DONIZETE DOS SANTOS ${ }^{2}$ \\ CELESTE MARIA PATTO DE ABREU ${ }^{3}$ \\ ANGELITA DUARTE CORREA ${ }^{3}$ \\ JOSÉ ZILTON LOPEZ SANTOS ${ }^{4}$
}

\begin{abstract}
RESUMO - Neste trabalho estudaram-se os teores de alguns nutrientes da fruta-de-lobo (Solanum lycocarpum St. Hil.) madura, comparando-os com os de outros frutos comestíveis, visando ao seu aproveitamento alimentar. Os frutos utilizados neste estudo foram colhidos de plantas nativas no município de Perdões, Minas Gerais, no estádio verde maturo e armazenados durante 18 dias à temperatura ambiente no Laboratório de Bioquímica do Departamento de Química da Universidade Federal de Lavras. As amostras foram preparadas do dia zero (dia da colheita) ao $18^{\circ}$ dia, com intervalos de 2 dias entre os estágios de amadurecimento. $\mathrm{O}$ delineamento experimental utilizado foi o inteiramente casualizado com 4 repetições de 3 frutos. Os frutos foram la-
\end{abstract}

\begin{abstract}
vados com água destilada, descascados, tendo suas polpas picadas, congeladas em nitrogênio líquido e liofilizadas até massa constante. Os teores de açúcares solúveis totais e açúcares não-redutores aumentaram gradativamente com a diminuição dos teores de amido. Os teores de vitamina $\mathrm{C}$ também aumentaram gradativamente durante o amadurecimento. Os teores encontrados na fruta-de-lobo de vitamina $\mathrm{C}$, açúcares solúveis totais, sacarose, fósforo e ferro, comparados aos de outros frutos como abacaxi, banana, laranja, manga e outros, são equivalentes ou superiores aos dos frutos em questão, podendo-se concluir que o fruto da lobeira representa mais uma alternativa como fonte desses nutrientes.
\end{abstract}

TERMOS PARA INDEXAÇÃO: Amido, fósforo, vitamina C, fruta nativa, Solanum lycocarpum.

\section{NUTRITIONAL ANALYSIS OF "FRUTA-DE-LOBO" (Solanum lycocarpum St. Hil.) DURING THE RIPENING PROCESS}

\begin{abstract}
The contents of some nutrients in ripe "fruta-de-lobo" (Solanum lycocarpum St. Hil.) fruits were investigated and compared with those in other comestible fruits in order to estimate its alimentary utilization. The fruits utilized in this study were harvested from native plants in the rural perimeter of Perdões city, Minas Gerais State, in the stage of green maturation, and were stored during 18 days at room temperature in the Biochemistry Laboratory of the Department of Chemistry, UFLA. The samples were prepared from the day zero (day of the harvest) to the $18^{\text {th }}$ day, with intervals of 2 days between the stages of the maturation. The experiments were carried out in a
\end{abstract}

random way, with 4 repetitions with 3 fruits each. The fruits were washed with distiled water and peeled. The pulps were stinged, frozen in liquid nitrogen and lyophilized until constant mass. The contents of soluble total sugars and nonreducing sugars increased gradualy with the decrease of the contents of starch. The contents of vitamin $\mathrm{C}$ also increased gradualy during the ripening process. The contents of vitamin $\mathrm{C}$, soluble total sugars, sucrose, phosphorus and iron in "fruta-delobo" fruits were shown to be equivalent or higher than those reported in fruits like pineapple, banana, orange, mango and other, leading to the conclusion that "fruta-delobo" fruits are an alternative source of these nutrients.

\footnotetext{
1. Engenheiro Químico, mestre em Agronomia, concentração Agroquímica e Agrobioquímica, UNIVERSIDADE FEDERAL DE LAVRAS/UFLA, Caixa Postal 37, 37200-000 - Lavras, MG. enio@feq.unicamp.br

2. Engenheiro Agrônomo, D.S. Ciências, Professor Titular do Departamento de Química/UFLA.

3. Engenheiro Agrônomo, D.S. Ciências dos Alimentos, Professora Adjunta do Departamento de Química/UFLA.

4. Graduando do curso de Agronomia, aluno de iniciação científica do Departamento de Química/UFLA.
} 


\section{INTRODUÇÃO}

A espécie vegetal Solanum lycocarpum St. Hil., da família Solanaceae, popularmente conhecida como lobeira, cresce e se desenvolve em condições ambientais desfavoráveis, tais como terras ácidas e pobres em nutrientes. É capaz de suportar um clima árido e períodos de seca prolongados, resistindo ainda a ciclos anuais de queimadas feitas pelo homem (Campos, 1994). De acordo com Oliveira Filho \& Oliveira (1988), é uma espécie invasora em áreas devastadas pelo homem e em pastagens.

Existem no Estado de Minas Gerais duas espécies de fruta-de-lobo: a Solanum grandiflorum e a Solanum lycocarpum (Corrêa, 1984). A fruta-de-lobo é encontrada nas vegetações do tipo campo sujo, cerrado e cerradão (Silva et al., 1994), cujo período de florada compreende o ano inteiro, porém, com maior intensidade na estação chuvosa (Oliveira Filho \& Oliveira, 1988). As plantas podem apresentar de 40 a 100 frutos, cuja massa por fruto pode variar de 400 a $900 \mathrm{~g}$, com época de colheita de julho a janeiro (Silva et al., 1994).

A polpa do fruto maduro pode ser consumida in natura ou ser utilizada para se fazer geléias, e a casca e a polpa nesse estágio apresentam coloração amarelada (Silva et al., 1994). Esse fruto tem sido utilizado para produção de massas, substituindo o marmelo na preparação da marmelada e afirma-se que, empregado puro, apresenta vantagens no sabor e no poder alimentício (Hoehne, 1946; Corrêa, 1984).

O objetivo com este trabalho foi estudar os teores de alguns nutrientes da fruta-de-lobo madura, comparando-os com os teores de outros frutos maduros comestíveis, visando ao seu aproveitamento alimentar.

\section{MATERIAL E MÉTODOS}

Colheita dos frutos. Os frutos foram colhidos no perímetro rural da cidade de Perdões Minas Gerais, após as 16 horas, e imediatamente após a colheita e seleção (frutos com boas características externas de qualidade), 120 frutos devidamente embalados em sacos de papel foram transportados para Lavras Minas Gerais, distante $34 \mathrm{~km}$ do local de colheita. Em Lavras, os frutos foram armazenados à temperatura ambiente no Laboratório de Bioquímica do Departamento de Química da Universidade Federal de Lavras, durante 18 dias, tempo suficiente para o total amadurecimento do fruto.

Preparo das Amostras. As amostras foram preparadas do dia zero (dia da colheita) ao $18^{\circ}$ dia, com intervalos de 2 dias entre os estádios de amadurecimen- to. Para cada estádio de amadurecimento, foram selecionados 12 frutos. O delineamento experimental utilizado foi o inteiramente casualizado com 4 repetições de 3 frutos. Os frutos foram lavados com água destilada, descascados, tendo suas polpas picadas, congeladas em nitrogênio líquido e liofilizadas em Liofilizador Labconco Freeze Dry System/Freezone 4,5 até massa constante. Todas as amostras foram liofilizadas durante 3 dias, tempo suficiente para que as massas das amostras tornassem constantes. Após a liofilização, as amostras foram moídas em moinho refrigerado por 3 períodos de 3 segundos, sob rotação de $22.500 \mathrm{rpm}$, temperatura de $4^{\circ} \mathrm{C}$, sendo, em seguida, armazenadas em recipiente de vidro hermeticamente fechado e protegido da luz à temperatura ambiente e submetidas às seguintes análises:

- Extração de Açúcares: extraídos pelo método de Lane-Enyon (AOAC, 1990).

- Açúcares Solúveis Totais (AST), Açúcares NãoRedutores (ANR) e Açúcares Redutores (AR): foram analisados utilizando-se o método redutométrico de Noelting \& Bernfeld (1948).

- Extração de Amido: a extração e hidrólise de amido foram feitas segundo técnica citada por Arêas \& Lajolo (1980).

- Análise de Amido: a quantificação de amido hidrolisado à glicose foi feita segundo a técnica descrita por Dalqvist (1967).

- Extração de Vitamina C Total: a 0,2 g de polpa, foi adicionado um volume de $6 \mathrm{~mL}$ de ácido oxálico $0,5 \mathrm{~g} / 100 \mathrm{~mL}$ de água destilada, homogeneizado em politron por 1 minuto à temperatura ambiente $\mathrm{e}$ centrifugando a $15.000 \mathrm{~g}$ por 5 minutos também à temperatura ambiente. $\mathrm{O}$ sobrenadante constituiu a fonte de vitamina $\mathrm{C}$.

- Análise de Vitamina C Total: foi utilizado o método colorimétrico de Roe \& Kutether, citado por Strohecker \& Henning (1967).

- Análise de Minerais e Nitrogênio: os minerais cálcio, magnésio, manganês, cobre, zinco e ferro foram determinados por absorção atômica; o fósforo, por espectrofotometria; o potássio, por fotometria de chama e o enxofre, por turbidimetria, sendo a quantificação de nitrogênio total feita por titulometria de acordo com as técnicas descritas por Malavolta et al. (1997).

- Análise de Proteína : o teor de proteína foi estimado pelo resultado obtido, multiplicando-se o teor de nitrogênio pelo fator 6,25 , de acordo com a técnica descrita por Malavolta et al. (1997). 


\section{RESULTADOS E DISCUSSÃO}

A desidratação das amostras ocorreu após 3 dias de liofilização, tempo suficiente para que a massa da amostra permanecesse constante, retirando das amostras $71,4 \%$ de umidade.

Os teores dos AST encontrados para o fruto verde (dia 0) e maduro (dia 18) foram respectivamente 2,61 e 11,02 g de glicose/100 g de polpa fresca (Figura 1). Observou-se um incremento nos teores de açúcares solúveis totais até os 10 dias de amadurecimento, e nesse estágio, foi encontrado o maior teor de AST, ou seja, $11,20 \mathrm{~g}$ de glicose/100 $\mathrm{g}$ de polpa fresca.

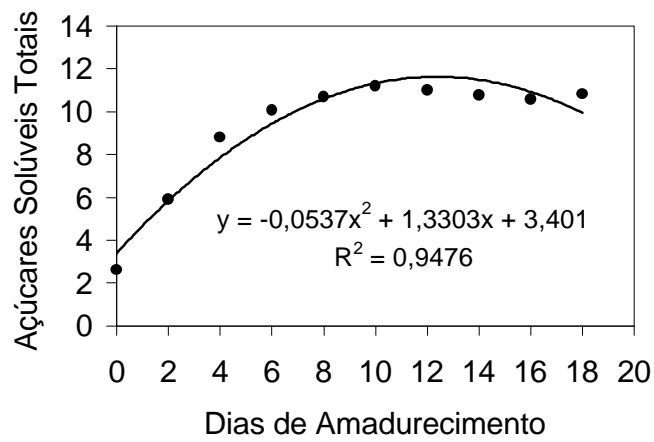

FIGURA 1 - Teores médios de açúcares solúveis totais (g de glicose/100 $\mathrm{g}$ de polpa fresca) durante 18 dias de amadurecimento da fruta-de-lobo (p 0,05).

O aumento nos teores dos AST encontrado durante o amadurecimento da fruta-de-lobo também foi observado durante o amadurecimento de banana (Vilas Boas, 1995), de manga (Lima, 1997) e de melão (Menezes, 1996).

As características inerente à banana (Vilas Boas, 1995), manga (Lima, 1997) e fruta-de-lobo (Figura 4), que explica o aumento nos teores de AST, são os altos teores de amido encontrados nos frutos verdes e sua conseqüente degradação durante o amadurecimento e conversão em açúcares simples. Concomitantemente ao aumento dos AST, observou-se um incremento na concentração dos ANR de 0,89 para 8,65 g de glicose/100 $\mathrm{g}$ de polpa fresca, respectivamente no fruto verde (dia 0 ) e maduro (dia 18), conforme Figura 2. A baixa concentração de ANR encontrada no fruto verde é devida principalmente a esse apresentar baixo teor de sacarose, que é sintetizada com o amadurecimento. Os teores de açúcares redutores apresentaram aumentos e decréscimos durante o amadurecimento. Os maiores teores dos
AR $(2,29$ e $2,25 \mathrm{~g}$ de glicose/100 $\mathrm{g}$ de polpa fresca) foram observados respectivamente nos 6 dias e 8 dias de amadurecimento (Figura 3).

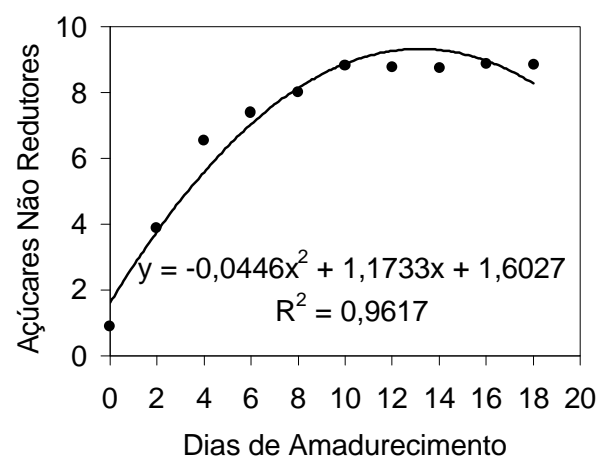

FIGURA 2 - Teores médios de açúcares não redutores (g de glicose/100 g de polpa fresca) durante 18 dias de amadurecimento da fruta-de-lobo ( $\mathrm{p} 0,05)$.

No fruto verde (dia 0), o teor de AR foi de 1,67 g de glicose/100 g de polpa fresca (Figura 3), apresentando-se maior que o teor de ANR, que foi de $0,89 \mathrm{~g}$ de glicose/100 $\mathrm{g}$ de polpa fresca (Figura 2). Essa baixa concentração de ANR é devida, principalmente, ao fato de o fruto verde apresentar baixo teor de sacarose.

A partir do $2^{\circ}$ dia até o estádio final, os teores de ANR (Figura 2) foram superiores aos teores de AR (Figura 3), sugerindo haver síntese de sacarose durante o amadurecimento do fruto.

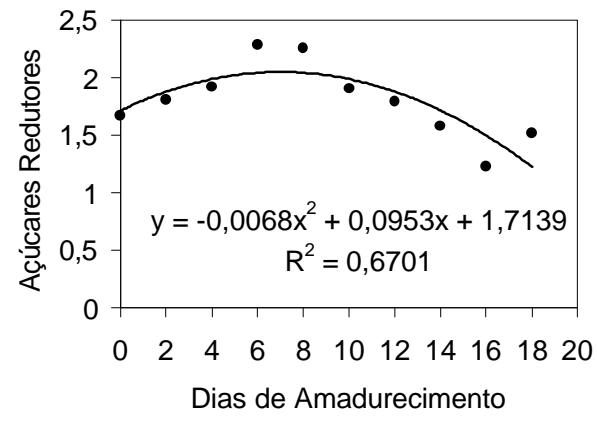

FIGURA 3 - Teores médios de açúcares redutores (g de glicose/100 g de polpa fresca) durante 18 dias de amadurecimento da fruta-de-lobo (p 0,05). 
O teor médio de AR encontrado neste estudo foi de $1,79 \mathrm{~g}$ de glicose/100 $\mathrm{g}$ de polpa fresca. Corrêa et al. (2000), estudando os constituintes químicos da fruta-de-lobo durante 20 dias de maturação, não encontraram diferença significativa nos teores de açúcares redutores, cujo teor médio foi de 1,23 g de glicose/100 g de polpa fresca. Essas diferenças podem ser explicadas provavelmente pelas diferentes épocas em que os frutos foram colhidos, pelos tipos de solos nos quais as plantas se desenvolveram e pelas condições de armazenamento dos frutos durante o amadurecimento.

Foram encontrados o teor máximo de amido na polpa do fruto verde (dia 0) de 19,53 e o teor mínimo no fruto maduro (dia 14) de $1,82 \mathrm{~g}$ de glicose/100 g de polpa fresca (Figura 4). Resultado semelhante foi encontrado por Lizada et al. (1990) que, num estudo com bananas, observaram que com o avanço da maturação até o completo amadurecimento, o amido é hidrolisado, resultando em enriquecimento no teor de açúcares na polpa madura. Em outro estudo também com bananas, Vilas Boas (1995) encontrou teores de amido da ordem de 21 a $1,7 \mathrm{~g}$ de glicose/100 g de polpa nos frutos verde e maduro, respectivamente. Com mangas, Lima (1997) observou que o conteúdo máximo de amido no mesocarpo fisiologicamente maturo diminuiu até o final do período de armazenamento.

$\mathrm{O}$ conteúdo de vitamina $\mathrm{C}$ total (ácido ascórbico e ácido dehidroascórbico) aumentou significativamente, indicando síntese dessa vitamina durante o amadurecimento. Os teores de vitamina C total encontrados, respectivamente, no fruto verde (dia 0) e maduro (dia 18) foram de 35,64 e $85,12 \mathrm{mg}$ de ácido ascórbico/100 g de polpa fresca (Figura 5).

$\mathrm{O}$ aumento na concentração de vitamina $\mathrm{C}$ total durante a maturação foi acompanhado por aumento no conteúdo de açúcares solúveis totais AST (Figura 1). O ácido ascórbico é, estruturalmente, um dos componentes vitamínicos mais simples encontrados em plantas. É uma lactona de açúcar ácido que é sintetizado em plantas a partir de glicose ou outros carboidratos simples (Kays, 1991). Vários outros frutos apresentam aumento dos teores de vitamina $\mathrm{C}$ durante o seu amadurecimento, dentre eles estão a goiaba, mamão (Seymour et al., 1993), melão (Menezes, 1996) e abacaxi (Abreu, 1991).

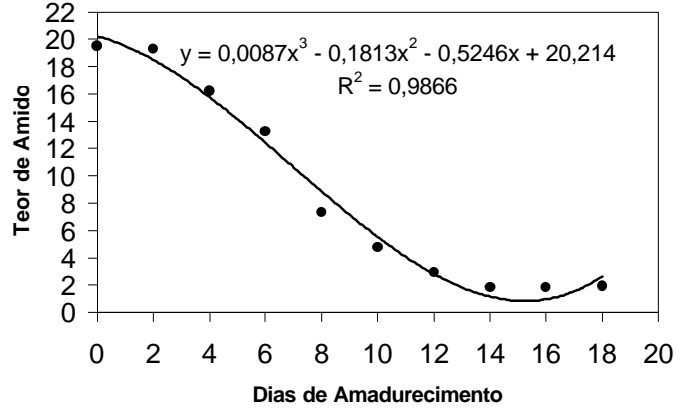

FIGURA 4 - Teor médio de amido (g de glicose/100 $\mathrm{g}$ de polpa fresca) durante 18 dias de amadurecimento da fruta-de-lobo ( $\mathrm{p} 0,05)$.

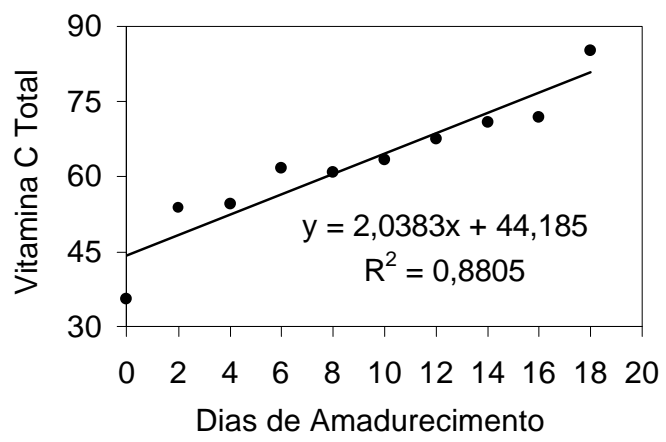

FIGURA 5 - Teores médios de vitamina C total (mg de ácido ascórbico/100 g de polpa fresca) durante 18 dias de amadurecimento da fruta-de-lobo (p 0,05).

Os conteúdos de nitrogênio, proteína e minerais analisados durante o amadurecimento da fruta-de-lobo estão apresentados na Tabela 1, com exceção do cálcio, que não foi encontrado na composição química do fruto.

Pode-se observar que na fruta-de-lobo foram encontrados teores de nutrientes equivalentes aos dos outros frutos ou até mesmo superiores, como é o caso dos teores de vitamina $\mathrm{C}$, exceto quando comparados com a goiaba (Tabela 2).

Quanto aos teores de minerais, a fruta-de-lobo pode ser usada como uma boa fonte de fósforo, já que, comparado aos outros frutos, o maior teor de fósforo foi encontrado na fruta-de-lobo. 
TABELA 1 - Teores médios de nitrogênio e proteína (g/100 g de polpa fresca) e de fósforo, potássio, magnésio, enxofre (g/100 de polpa fresca), cobre, manganês, zinco e ferro (mg/100 g de polpa fresca) durante o amadurecimento da fruta-de-lobo e respectivos coeficientes de variação.

\begin{tabular}{|c|c|c|c|c|c|c|c|c|c|c|}
\hline Dias & Nitrogênio & Proteína & Fósforo & Potássio & Magnésio & Enxofre & Cobre & Manganês & Zinco & $\begin{array}{c}\text { Fer- } \\
\text { ro }\end{array}$ \\
\hline 0 & 0,55 & 3,47 & 0,027 & 0,46 & 0,012 & 0,082 & 0,41 & 0,120 & 0,31 & 1,46 \\
\hline 2 & 0,55 & 3,20 & 0,029 & 0,48 & 0,014 & 0,107 & 0,40 & 0,150 & 0,43 & 1,20 \\
\hline 4 & 0,51 & 3,20 & 0,027 & 0,52 & 0,014 & 0,086 & 0,39 & 0,175 & 0,41 & 1,25 \\
\hline 6 & 0,56 & 3,51 & 0,036 & 0,43 & 0,014 & 0,087 & 0,34 & 0,272 & 0,27 & 1,17 \\
\hline 8 & 0,49 & 3,06 & 0,036 & 0,57 & 0,014 & 0,086 & 0,32 & 0,175 & 0,29 & 1,16 \\
\hline 10 & 0,55 & 3,43 & 0,038 & 0,55 & 0,014 & 0,096 & 0,38 & 0,147 & 0,32 & 1,21 \\
\hline 12 & 0,51 & 3,21 & 0,038 & 0,62 & 0,013 & 0,094 & 0,39 & 0,187 & 0,31 & 1,04 \\
\hline 14 & 0,52 & 3,24 & 0,041 & 0,65 & 0,013 & 0,102 & 0,42 & 0,075 & 0,35 & 1,25 \\
\hline 16 & 0,56 & 3,53 & 0,039 & 0,65 & 0,013 & 0,079 & 0,38 & 0,092 & 0,27 & 1,56 \\
\hline 18 & 0,59 & 4,37 & 0,044 & 0,76 & 0,016 & 0,089 & 0,40 & 0,155 & 0,31 & 1,14 \\
\hline $\begin{array}{l}\text { Média } \\
\text { Geral }\end{array}$ & 0,539 & 3,422 & 0,0355 & 0,569 & 0,0137 & 0,0908 & 0,383 & 0,1548 & 0,327 & 1,244 \\
\hline $\begin{array}{l}\mathrm{CV}^{*} \\
(\%)\end{array}$ & 11,89 & 16,81 & 9,06 & 18,75 & 18,44 & 15,90 & 11,34 & 14,18 & 8,28 & 6,53 \\
\hline
\end{tabular}

\section{* Coeficiente de variação}

TABELA 2 - Teores médios de vitamina $C$ (mg/100 g de polpa fresca), açúcares solúveis totais (g de glicose/100g de polpa fresca), sacarose (g de glicose/100g de polpa fresca), cálcio, fósforo e ferro (mg/100 g de polpa fresca) da fruta-de-lobo madura, comparados com os de alguns frutos maduros.

\begin{tabular}{lcccccc}
\hline \multicolumn{1}{c}{ Frutos } & Vitamina C & AST & Sacarose & Cálcio & Fósforo & Ferro \\
\hline Abacaxi & 61 & 13,5 & 5,8 & 18 & 8 & 0,5 \\
Banana & 14 & 15,4 & 2,0 & 15 & 26 & 2,0 \\
Figo & 4 & 15,6 & 1,5 & 50 & 30 & 0,5 \\
Fruta-de-lobo & 85 & 11,0 & 8,6 & - & 35,5 & 1,2 \\
Goiaba & 218 & 5,6 & 1,3 & 22 & 26 & 0,7 \\
Laranja & 59 & 9,6 & 4,6 & 34 & 20 & 0,7 \\
Manga & 53 & 21,0 & 14,4 & 12 & 12 & 0,8 \\
Mamão & 46 & 8,4 & 1,1 & 20 & 13 & 0,4 \\
Pêssego & 6 & 5,3 & 3,9 & 9 & 24 & 4,4 \\
Tangerina & - & 1,9 & 4,9 & - & - & - \\
Tomate & 23 & 2,5 & 0,1 & 7 & 24 & 0,6 \\
Uva & - & 18,5 & 2,5 & - & - & - \\
\hline
\end{tabular}

\section{Adaptado de Chitarra e Chitarra (1990).}




\section{CONCLUSÕES}

Os teores encontrados na fruta-de-lobo de vitamina C, AST, sacarose, fósforo e ferro, comparados aos de outros frutos, como abacaxi, banana, laranja, manga entre outros, são equivalentes ou superiores aos dos frutos em questão, podendo-se concluir que o fruto da lobeira representa mais uma alternativa como fonte desses nutrientes.

\section{REFERÊNCIAS BIBLIOGRÁFICAS}

ABREU, C. M. P. Alterações no escurecimento interno e na composição química do abacaxi c.v. Smoth cayenne durante o seu amadurecimento com e sem refrigeração. 1991. 72 f. Dissertação (Mestrado em Ciência dos Alimentos) - Escola Superior de Agricultura de Lavras, Lavras, 1991.

ARÊAS, J. A. G.; LAJOLO, F. M. Determinação enzimática específica de amido, glicose, frutose e sacarose em bananas preclimatéricas e climatéricas. Anais de Farmácia e Química de São Paulo, São Paulo, v. 20, n. 1/2, p. 307-318, jan./dez. 1980.

ASSOCIATION OF OFFICIAL ANALYTICAL CHEMISTS. Official methods of analysis of the Association of the Analytical Chemistry. 15. ed. Arlington, $1990.2 \mathrm{v}$.

CAMPOS, J. M. O eterno plantio: um reencontro com a natureza. São Paulo: Pensamento, 1994. 250 p.

CORRÊA, A. D.; ABREU, C. M. P. de.; SANTOS, C. D.; RIBEIRO, L. J. Determinação de alguns constituinte químicos de interesse nutricional da fruta-de-lobo (Solanum lycocarpum St. Hil.). Ciências Agrotécnicas, Lavras, v. 24, n. 1, p. 130-135, jan./mar. 2000.

CORRÊA, M. P. Dicionário de plantas úteis do Brasil e exóticas cultivadas. Brasília: Ministério da Agricultura/Instituto Brasileiro de Desenvolvimento Florestal, 1984. $6 \mathrm{v}$.

DALQVIST, A. Assay of intestinal disacaridases. Analytical Biochemistry, New York, v. 22, p. 99-107, 1967.

HOEHNE, F. C. Frutas indígenas. São Paulo: Secretaria da Agricultura, Indústria e Comércio, 1946. 429 p.

KAYS, S. J. Postharvest phisiology of perishable plant products. New York: Na Avi Book, 1991. 532 p.
LIMA, L. C. O. Tecido esponjoso em manga 'Tommy Atkins': transformações químicas e bioquímicas no mesocarpo durante o armazenamento. 1997. 148 p. Tese (Doutorado em Ciência dos Alimentos) - Universidade Federal de Lavras, Lavras, 1997.

LIZADA, M. C. C.; PANTASTICO, E. B.; SHUKOR, A. R. A.; SABARI, S. D. Ripening of banana: changes during ripening in banana. In: HASSAN, A.; PANTASTICO, E. B. (Eds.). Banana fruit development, postharvest physiology, handling and marketing, in ASEAN. Boston, [s.n.], 1990. cap. 5, p. 65-84.

MALAVOLTA, E.; VITTI, G. C.; OLIVEIRA, S. A. Avaliação do estado nutricional das plantas: princípios e aplicações. Piracicaba: Potafos, 1997. 319 p.

MENEZES, J. B. Qualidade pós-colheita do melão tipo 'Galia' durante a maturação e o armazenamento. 1996. 171 f. Tese (Doutorado em Ciência dos Alimentos) - Universidade Federal de Lavras, Lavras, 1996.

NOELTING, G.; BERNFELD, P. Sur les enzimes amylolitiques. 111. La $\beta$-amilase: dosage d'activité et controle de I'absence d'a-amilase. Helvetica Chemica Acta, Basel, v. 31, p. 286-290, 1948.

OLIVEIRA FILHO, A. T.; OLIVEIRA, L. C. A. Biologia floral de uma população de Solanum lycocarpum St Hil. (solanaceae) em Lavras, MG. Revista Brasileira de Botânica, São Paulo, v. 11, n. 1/2, p. 23-32, dez. 1988.

SEYMOUR, G. B.; TAYLOR, J. E.; TUCKER, G. A. Biochemistry of Fruit Ripening. London: Chapman \& Hall, 1993. 454 p.

SILVA, J. A. de; SILVA, D. B. da; JUNQUEIRA, N. T. V.; ANDRADE, L. R. M. de. Frutas nativas dos cerrados. Brasília: EMBRAPA, 1994. 166 p.

STROHECKER, R.; HENNING, H. M. Analises de vitaminas: métodos comprobados. Madrid: Paz Montalvo, 1967. $428 \mathrm{p}$.

VILAS BOAS, E. V. B. Modificações pós-colheita de banana "prata" (Musa acuminata $x$ M. balbisiana grupo AAB) $\boldsymbol{\gamma}$-irradiada. 1995. 73 f. Dissertação (Mestrado em Ciência dos Alimentos) - Universidade Federal de Lavras, Lavras, 1995. 